\title{
MENINGKATKAN KEMAMPUAN MOTORIK KASAR ANAK MELALUI BERMAIN DENGAN MEDIA HULAHOOP PADA ANAK KELOMPOK B PAUD AL-SYAFAQOH KABUPATEN REJANG LEBONG
}

\author{
Reni Novitasari \\ reninovitasari52@gmail.com
}

M. Nasirun

$\underline{\text { h.m.nasirun@gmail.co.id }}$

Delrefi D.

an.refi@gmail.com

\begin{abstract}
The problem in this research is whether through the activity of playing with media hula hoop can improve motor abusive ability of child. The purpose of this Classroom Action Research is to develop gross motor skills in the jumping of children on the strength and balance effects on the group B children in PAUD Al-Syafaqoh Rejang Lebong District. This study proved that playing with hula hoop media can improve the development of gross motor abilities of children. Evidenced by the increase of Rough Motor Capacity in children, seen in the first cycle meeting I on the aspect of strength and balance aspects of the average value reached 2.27 with the criteria Enough, then in cycle II The third meeting reached 4.3 with the criteria Good.
\end{abstract}

Keywords: Ability Rough Motorik; Hula Hoop Media; Early Childhood.

\section{PENDAHULUAN}

UU No 20 Tahun 2003 tentang Sistem Pendidikan Nasional, Bab 1 Pasal 1 Butir 14 Pendidikan Anak Usia Dini tidak hanya sekedar wacana. Pendidikan Anak Usia Dini (PAUD) adalah suatu upaya pembinaan yang ditujukan kepada anak sejak lahir sampai dengan usia enam tahun yang dilakukan melalui pemberian rangsangan pendidikan untuk membantu pertumbuhan dan perkembangan jasmani dan rohani agar anak memiliki kesiapan dalam memasuki pendidikan lebih lanjut (Departemen Pendidikan Nasional, 2003:3).

Pada Permendikbud Nomor 146 Tahun 2014 Tentang Kurikulum 2013 Pendidikan Anak Usia Dini Pasal 5 menjelaskan bahwa program-progran pengembangan yang mencakup; 1) Nilai
Agama dan Moral; 2) Fisik-Motorik; 3) Kognitif; 4) Bahasa; 5) Sosial Emosional dan 6) Seni.

Mengingat luasnya yang harus dioptimalkan, peneliti hanya meneliti Motorik kasar (gross motor) yaitu aktifitas yang membutuhkan koordinasi sebagian besar tubuh anak (Sujiono 2014 :1.13). Santrock (2011:209), menyatakan motorik kasar (gross motor skill) yang merupakan keterampilan yang melibatkan aktivitas otot besar seperti tangan seseorang untuk bergerak dan berjalan. Perkembangan motorik anak juga tidak dapat dilepaskan dari aspek-aspek pokok. Adapun aspekaspek pokok dalam pembelajaran motorik kasar pada anak adalah kekuatan, daya tahan kardiovaskuler (ketahanan), power, kecepatan, ketahanan, kelincahan, 
keseimbangan, waktu reaksi dan koordinasi (Decaprio, 2013:41).

Permendikbud Nomor 137 Tahun 2014 Tentang Standar nasional Pendidikan Anak Usia Dini Pasal 8 mengenai Standar Tingkat Pencapaian Perkembangan, menyatakan perkembangan motorik kasar anak usia 5-6 tahun yaitu: 1) Melakukan gerakan tubuh secara terkoordinasi untuk melatih kelenturan, keseimbangan, dan kelincahan; 2) Melakukan koordinasi gerakan mata-kaki-tangan-kepala dalam menirukan tarian atau senam; 3) Melakukan permainan fisik dengan aturan; 4) Terampil menggunakan tangan kanan dan kiri; 5) Melakukan kegiatan kebersihan diri. Oleh sebab itu, perkembangan kemampuan motorik kasar anak perlu di stimulasi dan di beri rangsangan agar dapat meningkat dengan kegiatan bermain dengan media hula hoop.

Pada kenyataan yang ditemui di PAUD Al-Syafaqoh dimana perkembangan motorik anak diabaikan atau bahkan dilupakan orang tua pembimbing atau bahkan pendidik sendiri, sehingga ditemukan kasus dimana anak tidak memiliki keinginan untuk melakukan perkembangan jasmaninya bahkan sebagian anak merasa kegiatan tersebut tidak menyenangkan. Konsentrasi pada perkembangan mental dan intelektual ini sering terjadi pengorbanan kecerdasan fisik, suatu unsur yang sering diabaikan padahal penting bagi perkembangan menuju manusia yang serba bisa. Hal ini ditandai dengan beberapa kondisi, setelah peneliti melakukan observasi dari 10 orang anak di dalam kelas hanya 4 orang anak saja yang mampu dan antusias dalam menirukan gerakan berlari, meloncat, berjinjit, menyepak, dan menendang bola.

Berdasarkan latar belakang permasalahan tersebut, maka dapat dirumuskan masalah dalam penelitian adalah:
1. Bagaimana meningkatkan kemampuan motorik kasar anak melalui media hula hoop pada anak kelompok B di PAUD Al-Syafaqoh Kabupaten Rejang Lebong?

2. Apakah dengan bermain melalui hula hoop kemampuan motorik kasar anak dapat meningkat?

Berdasarkan rumusan masalah tersebut, maka tujuan dalam penelitian ini adalah:

1. Untuk mengetahui bagaimana meningkatkan kemampuan motorik kasar anak melalui media hula hoop pada anak kelompok B di PAUD AlSyafaqoh Kabupaten Rejang Lebong

2. Untuk mengetahui apakah melalui bermainan hula hoop dapat meningkatkan aspek kekuatan dan keseimbangan pada aspek motorik kasar anak.

Menurut Risnawati (2008:24), kemampuan adalah kecakapan untuk melakukan suatu tugas khusus dalam kondisi yang telah ditentukan. Pada proses pembelajaran perolehan kemampuan merupakan tujuan dari pembelajaran. Di dalam kamus bahasa Indonesia (2007:707), kemampuan berasal dari kata "mampu" yang beratri kuasa. Kemampuan adalah suatu kesanggupan dalam melakukan sesuatu. Seseorang dikatakan mampu apabila ia bisa melakukan sesuatu yang harus ia lakukan.

Hasninda (2014:52), menyatakan motorik kasar adalah gerakan tubuh yang menggunakan sebagian besar atau seluruh anggota tubuhyang dipengaruhi oleh kematangan anak itu sendiri. Menurut Sujiono dan Sujiono (2010: 45), menyatakan motorik kasar adalah aktifitas gerak tubuh yang melibatkan otot besar seperti merayap, berguling, merangkak, duduk, berdiri, berjalan, lari, lompat, dan berbagai aktivitas menendang serta aktivitas melempar dan menangkap.

Dari pengertian-pengertian tersebut dapat disimpulkan bahwa kemampuan 
adalah kesanggupan atau kecakapan seorang individu dalam menguasai suatu keahlian dan digunakan untuk menggerakkan dan menyeimbangkan tubuh anak seperti merayap, berguling, merangkak, duduk, berdiri, berjalan, lari, lompat, dan berbagai aktivitas menendang serta aktivitas melempar dan menangkap yang berpengaruh terhadap otot-otot besar anak.

Menurut Sumantri (2005:9), motorik kasaar memiliki beberapa tujuan yaitu: 1) Mampu meningkatkan keterampilan gerak; 2) Mampu memelihara dan meningkatkan kebugaran jasmani; 3) Mampu menanamkan sikap percaya diri; 4) Mampu bekerja sama dan 5) Mampu berprilaku disiplin, jujur dan sportif.

Pada buku "Balita dan Masalah Perkembangannya" (dalam Sujiono 2014:1.4), secara umum terdapat tiga tahapan perkembangan keterampilan motorik anak pada usia dini, yaitu :

1. Tahap Kognitif. Anak berusaha memahami keterampilan motorik serta apa saja yang dibutuhkan untuk melakukan gerakan suatu gerakan tertentu. Pada tahap ini, dengan kesadaran mentalnya anak berusaha mengembangkan strategi tertentu untuk mengingat gerakan serupa yang pernah dilakukan pada masa lalu.

2. Tahap Asosiatif. Anak belajar dengan cara coba meralat olahan pada penampilan atau gerakan akan dikoreksi agar tidak melakukan kesalahan kembali di masa mendatang. Tahap ini adalah perubahan strategi dari tahap sebelumnya, yaitu dari apa yang harus dilakukan menjadi bagaimana melakukannya.

3. Tahap autonomus. Gerakan yang ditampilkan anak merupakan respons yang lebih efesien dengan sedikit kesalahan. Anak sudah menampilkan gerakan secara otomatis.
Menurut Permendikbud 146 Tentang Kurikulum 2013 Pendidikan Anak Usia Dini Pasal 6 mengenai Tingkat Pencapaian Perkembangan Anak disusun berdasarkan kelompok usia menyatakan karakteristik motorik kasar anak usia 5-6 tahun yaitu: 1) Melakukan berbagai kegiatan terkoordinasi secara terkontrol, seimbang dan lincah; 2) melakukaan kegiatan yang menunjukkan anak mampu melakukan gerakan mata, tangan, kaki, kepala secara terkoordinasi dalam menirukan berbagai gerakan yang teratur (missal: senam dan tarian); 3) Melakukan kegiatan yang menunjukkan anak mampu melakukan permainan fisik dengan aturan; 4) Melakukan kegiatan yang menununjang anak mampu terampil menggunakan tangan kanan dan tangan kiri dalam berbagai aktivitas. Indikartor dalam kemampuan motorik kasar anak di atas dapat di kembangkan melalui bermain

Menurut Piaget dalam Sujiono (2012:144), mengatakan bermain adalah suatu kegiatan yang dilakukan berulangulang dan menimbulkan kesenangan atau kepuasan bagi diri anak.

Media yang digunakan dalam pembelajaran anak usia dini bermacammacam dari media visual, media audio, media audio visual, media lingkungan dan media permainan. Salah satu media permainan adalah hula hoop. Hula hoop adalah benda yang berbentuk lingkaran yang dengan bahan lunak yang dapat digunakan untuk mengembangkan berbagai macam aktivitas gerak atau permainan yang bisa dilakukan secara perorangan atau berpasangan bahkan berkelompok, dan secara umum dapat dilakukan di mana saja (Faruq, 2009:2).

Berdasarkan kajian teori maka dapat dirumuskan hipotesis pada Penelitian Tindakan Kelas (PTK) ini yaitu, "Melalui bermain dengan media Hula Hoop maka kemampuan motorik anak dapat berkembang secara optimal". 


\section{METODE}

Penelitian yang dilaksanakan adalah penelitian tindakan kelas. Penelitian ini dilaksanakan dengan dua siklus. Setiap siklus pada penelitian tindakan terdiri dari empat tahap, yaitu: 1) Perencanaan, 2) Pelaksanaan, 3) pengamatan, 4) Refleksi.

Penelitian ini dilakukan di PAUD AlSyafaqoh kabupaten rejang lebong. Subjek dalam penelitian ini berjumlah 10 anak yang terdiri dari 4 anak laki-laki dan 6 anak perempuan. Teknik pengumpulan data pada penelitian ini menggunakan lembar observasi, dilakukan dengan memberi penilaian terhadap kegiatan bermain dengan media hula hoop yang dilakukan. Sedangkan lembar observasi penilaian guru digunakan untuk mengetahui kegiatan belajar mengajar.

Teknik analisa data dilakukan pada saat anak melakukan kegiatan bermain sehingga menggunakan untuk mendapatkan data dalam meningkatkan perkembangan kemampuan motorik kasar anak kelompok B PAUDAl-Syafaqoh Kabupaten Rejang Lebong. Penelitian ini menggunakan analisis rata-rata dan ketuntasan belajar.

Penelitian tindakan kelas ini dikatakan berhasil apabila kegiatan bermain dengan media hula hoop mampu meningkatkan aspek perkembangan motorik kasar anak yang diharapkan yaitu: kekuatan anak dalam melompat tanpa berhenti dan keseimbangan anak saat meloncat tidak terjtuh dan menyenggol hula hoop dapat meningkat dan mencapai $75 \%$ dari jumlah anak.

\section{HASIL DAN PEMBAHASAN}

Berdasarkan hasil observasi pada peningkatan perkembangan motorik kasar anak antara siklus I pertemuan ke-3 dan siklus II pertemuan ke-3 mengalami peningkatan. Pada siklus I pertemuan ke-3 rata-ratanya mencapai 3,325 dengan ketuntasan klasikal $66,60 \%$ berada pada kriteria Cukup, sedangkan pada siklus II pertemuan ke-3 rata-ratanya mencapai 4,3 dengan ketuntasan klasikal $86 \%$ dengan kriteria Baik.

Tabel 1. Rekapitulasi Siklus I dan Siklus II Observasi Bermain Anak Mengunakan Media Hula Hoop

\begin{tabular}{|c|c|c|c|c|}
\hline $\begin{array}{l}\text { Nama } \\
\text { Anak }\end{array}$ & $\begin{array}{l}\text { Siklus } \\
\text { I PK- } 3\end{array}$ & $\begin{array}{c}\text { Siklus II } \\
\text { PK-3 }\end{array}$ & $\begin{array}{l}\text { Rata- } \\
\text { rata }\end{array}$ & KK \\
\hline Dv & 3,875 & 5 & 4,4375 & $B$ \\
\hline Do & 3,875 & 5 & 4,4375 & B \\
\hline $\mathrm{Fm}$ & 3,625 & 4,5 & 4,0625 & B \\
\hline $\mathrm{Aq}$ & 3 & 4,5 & 3,75 & B \\
\hline Dw & 3,375 & 4,5 & 3,9375 & B \\
\hline $\mathrm{Dz}$ & 3,375 & 4 & 3,6875 & $B$ \\
\hline Cka & 3,375 & 4 & 3,6875 & B \\
\hline Zhr & 3,375 & 4 & 3,6875 & B \\
\hline $\mathrm{Kr}$ & 3 & 4 & 3,5 & $C$ \\
\hline $\mathrm{Au}$ & 3 & 3,5 & 3,25 & $C$ \\
\hline Jmlh & 33,25 & 4,3 & \multirow{3}{*}{\multicolumn{2}{|c|}{ Tercapai }} \\
\hline$\Pi$ & 3,325 & 4,3 & & \\
\hline $\begin{array}{c}\text { Ketunt } \\
\text { asan } \\
\text { klasikal }\end{array}$ & $\begin{array}{c}66,60 \\
\%\end{array}$ & $86 \%$ & & \\
\hline
\end{tabular}

Selain observasi yang dilakukan pada anak peneliti juga melakukan analisis data pada observasi aktivitas guru pada proses pembelajaran dalam meningkatkan keterampilan motorik kasar anak melalui kegiatan bermain melalui media hula hoop pada tabel 2 ini:

Tabel 2. Hasil Perbandingan Observasi Guru

\begin{tabular}{|c|c|c|}
\hline \multicolumn{2}{|c|}{$\begin{array}{c}\text { Skor yang di } \\
\text { peroleh }\end{array}$} & \multirow{2}{*}{ Kriteria } \\
\cline { 1 - 2 } Siklus & Siklus II & \\
I PK-3 & PK-3 & \\
\hline 3,81 & 4,125 & Meningkat \\
\hline
\end{tabular}

Berdasarkan pengelolaan data yang telah dilakukan, bahwa melalui kegiatan bermain melalui hula hoop dapat meningkatkan kemampuan motorik kasar dan dapat dilihat berdasarkan hasil pertemuan baik secara klasikal maupun individu pada siklus I dan II. Meskipun demikian keberhasilan dalam meningkatkan kemampuan motorik kasar tidak terjadi secara langsung melainkan secara bertahap melalui berbagai tindakan hingga mencapai indikator keberhasilan. Hal ini dikarenakan 
adanya perbaikan-perbaikan yang dilakukan oleh peneliti/guru dan teman sejawat demi meningkatkan kemampuan motorik kasar anak.

Sumantri (2005: 70), menyatakan bahwa peningkatan motorik terjadi sejalan dengan meningkatnya kemampuan koordinasi mata, tangan, dan kaki. Perkembangan motorik bisa terjadi dengan baik apabila anak memperoleh kesempatan yang cukup besar untuk melakukan aktivitas fisik dalam bentuk gerakan-gerakan yang melibatkan seluruh tubuh.

Dalam penelitian ini peningkatan kemampuan motorik kasar anak melalui bermain menggunakan hula hoop secara sederhana dan menyenangkan. Sesuai dengan pendapat Tedjasaputra (2001: 11), menyatakan bahwa bermain memungkinkan anak untuk bereksplorasi terhadap kemungkinan yang ada untuk meningkatkan kemampuan motorik kasar maka dilakukan dengan kegiatan yang menyenangkan, sehingga secara tidak langsung anak tertarik dan menikmati permainan atau kegiatan tersebut. Kegiatan bermain menggunakan hula hoop adalah kegiatan yang sederhana dan tidak membuat anak menjadi bosan karena anak selalu ingin mengulanginya dan membuat anak menjadi percaya diri.

Berdasarkan hasil tindakan siklus I dan siklus II dapat terlihat perolehan kemampuan bermain anak melalui hula hoop mengalami peningkatan khususnya pada aspek kekuatan dan aspek keseimbangan. Pemerolehan nilai rata-rata anak berbeda, terlihat pada tabel observasi anak di atas siklus I pertemuan ke-3 dan siklus II pertemuan ke- 3 terdapat 8 orang anak yang mendapatkan kriteria Baik (B) yaitu: Dv dengan nilai rata-rata 4,44. Dv sangat antusias dalam melakukan kegiatan bermain hula hoop pada saat meloncat keseimbangan maupun kekuatan terlihat sangat jelas dengan tidak menyentuh hula hoop dan juga sangat cepat saat berbalik ke titik awal lompatan dan tidak berhenti; Do dengan nilai rata-rata 4,44. Do merupakan anak yang sangat menyukai aktivitas olah tubuh, terlihat dari observasi awal Do mendengarkan arahan dari guru dan melakukan gerakan meloncat dengan sedikit kesalahan; Fm dengan nilai rata-rata 4,04. Sama seperti Do Fm sangat menyukai gerakan yang menggunakan anggota tubuh seperti tangan dan kaki; Aq dengan nilai rata-rata 3,75 dan Dw dengan nilai rata-rata 3,93. Aq dan Dw adalah anak-anak yang unggul dalam bidang intelektual dan kurang ingin melakukan gerakan motorik kasar. Namun, Aq dan Dw termasuk anak yang sangat suka dengan reward sehingga dengan memberikan rewad kepada Aq dan Dw anak-anak tersebut tertarik pada kegiatan motorik kasar; Dz dengan nilai rata-rata 3,68 . Dz anak laki-laki yang postur tubuhnya kecil di bandingkan dengan anakanak seusianya, sehingga sedikit kesulitan pada kegiatan melompat kedalam hula hoop. Karena bagi Dz jarak yang di tempuh terlalu jauh untuk melompat dari satu hula hoop ke hula hoop lainnya; Cka dengan nilai rata-rata 3,68 dan Zhr dengan nilai rata-rata 3,68 . Selain karna postur tubuh yang dimiliki Cka dan Dz melebihi berat badan pada anak seusianya Cka dan Dz juga mampu melakukan kegiatan bermain hula hoop walaupun terkadan gerakan yang dilakukan sedikit lambat. Dan juga terdapat 2 orang anak yang mendapatkan kriteria Cukup (C) yaitu: $\mathrm{Kr}$ dengan nilai rata-rata 3,5 dan Au dengan nilai rata-rata 3,25. $\mathrm{Kr}$ dan $\mathrm{Au}$ adalah anak-anak yang tidak terbiasa dengan gerakan motorik kasar, selain itu $\mathrm{Kr}$ dan $\mathrm{Au}$ tidak jarang mengabaikan arahan dari guru dan peraturan yang sudah disepakati bersama teman-teman lainnya. 


\section{PENUTUP}

\section{Simpulan}

Berdasarkan hasil penelitian yang telah dilakukan pada kelompik B PAUD AISyafaqoh kabupaten rejang lebong dapat disimpulkan bahwa :

1. Melalui kegiatan bermain dengan menggunakan hula hoop dapat meningkatkan aspek-aspek kemampuan motorik kasar anak. Aspek yang dinilai saat pelaksanaan bermain adalah aspek Kekuatan dan keseimbangan. Kegiatan bermain melompat kedalam hula hoop yang pertama diawali dengan mengenalkan alat bermain hula hoop lalu guru mencontohkan kepada anak gerakan melompat dan berbalik arak kedalam hula hoop dengan pola berbentuk lingkaran dan zig zag.

2. Melalui kegiatan bermain dengan menggunakan hula hoop dapat meningkatkan kemampuan motorik kasar anak. Pada siklus I pertemuan ke3 rata-rata nilai anak mencapai 3,6 dengan ketntasan belajar sebesar $72 \%$ dengan kriteria belum tuntas kemudian meningkat pada siklus II pertemuan ke3 rata-rata nilai anak menaapai 4,3 dengan ketuntasan belajar sebesar $86 \%$ dan dikatakan sudah tuntas. Hasil tersebut menunjukkan bahwa setiap siklus meningkat berarti dari hasil akhir yang diperoleh penelitian ini dapat di katakan berhasil karena telah mencapai indikator keberhasilan. Dengan demikian kegiatan bermain melalui hula hoop dapat meningkatkan kemampuan motorik kasar pada anak.

\section{Saran}

1. Bagi guru

Kegiatan bermain menggunakan hula hoop dapat digunakan anak untuk meningkatkan kemampuan motorik kasar anak, guru dapat menerapkan kegiatan bermain menggunakan hula hoop ini pada anak usia dini agar perkembangan kemampuan motorik kasar anak dapat ditingkatkan. Bermain menggunakan hula hoop merupakan cara yang digunakan untuk membuat anak lebih antusias dalam melakukan gerak motorik kasar, oleh sebab itu guru dapat melakukan kegiatan ini untuk mengembangkan kemampuan motorik kasar

2. Bagi Peneliti Selanjutnya

Kegiatan bermain menggunakan hulas hoop dapat dijadikan untuk referensi lebih disempurnakan kembali. Kegiatan bermain menggunakan hula hoop dapat divariasi dengan melakukan gerakan lain seperti melompat kedalam hulahop dan mendarat di matras. Aspek yang di teliti juga dapat dikembangkan kembali tidak hanya kelincahan dan keseimbangan terapi kekuatan dan fleksibilitas juga dapat di jadikan komponen penelitian selanjutnya.

\section{DAFTAR PUSTAKA}

Departemen pendidikan Nasional; 2003; Undang-Undang Republik Indonesia No 20 Tahun 2003 Tentang Sistem Pendidikan Nasional; Jakarta : Depdiknas

Decaprio, Richard; 2013; Aplikasi Pembelajaran Motorik Di Sekolah; Jakarta : DIVA Press

Faruq, Muhammad Muhyi. 2009. Permainan Pengembangan Kecerdasan Kinestetik Anak Dengan Media Hula Hoop. Jakarta: PT Gramedia Widiasarana Indonesia

Hasninda; 2014. Analisis Kebutuhan Anak Usia Dini. Jakarta Timur : PT. Luxima Metro Media

Permendikbud No 146. 2014. Tentang Kurikulum 2013 Pendidikan Anak Usia Dini. Kementrian Pendidikan dan kebudayaan Republik Indonesia 
Permendikbud No 137. 2014. Standar

Nasional Pendidikan Anak Usia

Dini. Kementrian Pendidikan dan

kebudayaan Republik Indonesia

Risnawati. 2008. Strategi Pembelajaran

Matematika. Pekanbaru: Suska Press

Sujiono, Yuliani Nurani. 2012. Konsep

Dasar Pendidikan Anak Usia Dini.

Jakarta: PT. Indeks

Santrock, Jhon W. 2011. Masa

Perkembangan Anak Edisi 11. Jakarta:

Salemba Humanika

Tedjasaputra, Maykr S. 2001. Bermain, Mainan, dan Permainan. Jakarta: Pt

Gramedia Widiasarana Indonesia 